\title{
ARQUITETURA EFÊMERA COMO CONTRIBUINTE PARA A DIVERSIDADE CULTURAL EM ESPAÇOS PÚBLICOS
}

\author{
Gustavo Casula, Yeda Ruiz Maria
}

Universidade do Oeste Paulista - UNOESTE, curso de Arquitetura e Urbanismo, Presidente Prudente, SP. E-mail: yedarm@hotmail.com

\begin{abstract}
RESUMO
O presente artigo tem como objetivo analisar a importância de estruturas arquitetônicas efêmeras em espaços de uso público fazendo com que tais locais possuam maior eficiência democrática. 0 artigo a seguir visa identificar a importância de um espaço público como abrangente de diferentes perfis sociais que se encontram nas cidades, que constantemente sofrem por diversos processos de modificações, além de destacar a influência do multiculturalismo encontrado nos municípios dos dias atuais. Buscou-se analisar principalmente a importância e o impacto que a arquitetura efêmera pode causar em seu local de inserção, por se tratar de estruturas facilmente adaptáveis, transportáveis e de materiais alternativos de baixo custo. Tal vertente arquitetônica pode assim seguir a lógica dos processos de mutação das cidades contemporâneas, além de referenciar os perfis multiculturais contemporâneos e consequentemente democratizar os espaços públicos através de técnicas incomuns às comumente vistas em tais locais.
\end{abstract}

Palavras-chave: Arquitetura Efêmera. Multiculturalismo. Espaço Público. Democrático.

\section{EPHEMERAL ARCHITECTURE AS A CONTRIBUTOR TO CULTURAL DIVERSITY IN PUBLIC SPACES}

\begin{abstract}
The aim of this article is to analyze the importance of ephemeral architectural structures in spaces of public use, making these places more democratic. The following article aims at identifying the importance of a public space as encompassing different social profiles found in the cities, which constantly suffer from various modification processes, in addition to highlighting the influence of multiculturalism found in the municipalities of today. We sought to analyze mainly the importance and the impact that the ephemeral architecture can cause in its place of insertion, since they are easily adaptable, transportable structures and of alternative materials of low cost. Such an architectural strand can thus follow the logic of the mutation processes of contemporary cities, as well as reference contemporary multicultural profiles and consequently democratize public spaces through techniques unusual to those commonly seen in such places.
\end{abstract}

Keywords: Ephemeral Architecture. Multiculturalism. Public Spaces. Democratic

\section{INTRODUÇÃO}

É possível observar que ao longo dos anos as cidades vêm sofrendo um forte processo histórico de imigração e migração, principalmente na contemporaneidade com as novas tecnologias e facilidade de acesso a informações.

Os espaços públicos, que segundo Jovchelovitch (1995), são de extrema importância nos processos de formação histórica da sociedade, por nesses locais ocorrerem diálogos fazendo com que os humanos saiam da individualidade de suas vidas privadas e descubram através coletividade assuntos importantes para o autoconhecimento da sociedade. Ainda segundo a autora, os espaços públicos são sustentados pela diversidade entre seus usuários, por esses locais serem responsáveis pela ação comunicativa entre o Um e o Outro. 
A arquitetura efêmera, marcada por ter um prazo de duração no espaço pré-estabelecido, e que quanto menor essa duração maior sua efemeridade tem como maior objetivo abrir um espaço para várias possibilidades, através de suas estruturas facilmente transportáveis, adaptáveis e/ou degradáveis, permitindo aos seus usuários uma multiplicidade de ações e experiências coletivas (PAZ, 2008).

Neste contexto, o presente artigo tem como objetivo analisar como estruturas arquitetônicas efêmeras podem contribuir para o enriquecimento da diversidade urbana principalmente no convívio em espaços públicos. Para tanto, faz-se necessário levantamentos teóricos e análises de obras arquitetônicas e urbanísticas com a finalidade de fundamentar o texto em questão.

\section{DIVERSIDADE URBANA - BREVE CONTEXTUALIZAÇÃO}

Uma das características mais relevantes das cidades brasileiras é a diversidade cultural e étnica que foram configuradas devido aos seus processos de colonização, imigração e, o mais significativo na atualidade, de globalização. A importância do multiculturalismo ${ }^{1}$ nos dias atuais gerou uma nova discussão sobre diversidade social, político, urbano, ambiental e humano, fazendo com que se retomasse a ideia de que o único fator de desenvolvimento fosse o financeiro (JÚNIOR; HASS, 2011).

Tal assunto é tema do Relatório de Desenvolvimento Humano de 2004, o qual é possível destacar o seguinte trecho:

Uma pessoa pode ter uma identidade de cidadania (por exemplo, ser francesa), de sexo (ser mulher), de raça (ser de origem chinesa), de origem regional (ser proveniente da Tailândia), de língua (ser fluente em tailandês, chinês e inglês, além de francês), política (ter ideias de esquerda), religiosa (ser budista), profissional (ser advogado), de localização (ser residente em Paris), de filiação desportiva (ser jogador de badminton e fanático de golfe), de gosto musical (adorar jazz e hip-hop), de preferência literária (gostar de romances policiais), de hábitos alimentares (ser vegetariana), etc. (ONU, 2004, p. 17)

O reconhecimento do multiculturalismo faz com que diversos grupos étnicos se sintam livres para expor suas ideias, realizar seus rituais culturais e/ou religiosos sem ter receio de expor sua identidade. Segundo d'Adesky (1997) isso deve ser feito com o apoio do Estado com o auxílio da Constituição por ser direito de cidadania a todos, por ser vital para que instituições públicas possam garantir que haja reconhecimento adequado de diversas culturas, preservando identidades culturais particulares através de liberdade de expressão, práticas religiosa, dentre outros. Além disso, para a sociedade em geral, o reconhecimento dessas diferenças culturais é positivo quando se trata do enriquecimento intelectual através de práticas espirituais e culturais por meio de organismos públicos. (D’ADESKY, 1997)

Um exemplo de bom uso do espaço urbano, permitindo que haja interação entre diversas classes sociais, além de integração com a cidade física é o Festival Todos ${ }^{2}$, que utiliza de uma política social para incentivar o multiculturalismo, obtendo sucesso anualmente, fazendo assim com que voltemos o olhar à importância da reinvenção das políticas sociais, ressaltando as mudanças arquitetônicas, urbanísticas, culturais, dentre outras, que ocorrem nas cidades durante o passar do tempo.

\footnotetext{
${ }^{1}$ O multiculturalismo é a necessidade de reconhecer o valor de cada cultura presente na sociedade, tratando com igualdade de cidadania e valorizando todas de maneira igualitária. (D'ADESKY, 1997)

2 Tal festival ocorre em Mouraria, bairro tradicional de Lisboa, e celebra a diversidade cultural dos novos e tradicionais cidadãos que ali se encontram (OLIVEIRA; PADILLA, 2012).

Colloquium Socialis, Presidente Prudente, v. 01, n. Especial 2, Jul/Dez, 2017, p.655-659. DOI: 10.5747/cs.2017.v01.nesp2.s0208
} 
É preciso ser flexível na hora de pensar soluções que integrem os diferentes perfis sociais que são encontrados nas comunidades. Sendo assim, a forma mais democrática, entendida por este trabalho, de abranger todas as classes da população é a intervenção em espaços públicos, com o intuito de ser acessível e chamar a atenção para a importância de se reconhecer todos os perfis culturais que são encontrados na sociedade contemporânea.

Para Gatti (2013) os espaços públicos contemporâneos possuem representatividade na vida urbana por não haver distinção de raças ou classes sociais, sendo palco de grandes encontros referentes à cultura, lazer, descanso, circulação, troca de informações, dentre outros (GATTI, 2013).

Jovchelovitch (1995) explica que sem os espaços públicos não haveria história, pois, são nesses locais que ocorrem os diálogos e fazem com que o ser humano saia da sua individualidade e descubra o que é pertinente para uma vida em conjunto, projetando ideias que auxiliem na construção do presente e do futuro, além de retomar a importância do passado. Ainda de acordo com Jovchelovitch (1995) esses encontros em espaços públicos são importantes para esquecer o Eu, buscar conhecimento sobre o Outro e assim formar o Nós, tão importante para o desenvolvimento em grupo e para que cada indivíduo visualize o quão necessária é a troca de experiências multiculturais.

A diversidade é fundamental para o bom funcionamento dos espaços públicos. Ser diferente movimenta a sociedade e faz com que cada indivíduo se interesse cada vez mais por conhecer as particularidades de viver em grupo (JOVCHELOVITCH, 1995).

Com a crescente busca por esses espaços públicos, assim como sua importância para a sociedade, o Estado se viu no papel de criar leis para auxiliar na visibilidade desses locais tão essenciais para a vida urbana com a finalidade de garantir que a vida particular não fosse o único interesse de uso e ocupação do solo.

Os espaços de usos públicos devem garantir à população o que é seu por direito e possuem um importante papel para melhorar o convívio da comunidade com uma nova vertente para a cidade utilizando de estruturas que permitam espaços flexíveis. Tais espaços devem se adaptar às varias possibilidades de convívio abrangendo os diferentes perfis dos moradores das cidades.

\section{ARQUITETURA EFÊMERA COMO INSTRUMENTO DE DIVERSIDADE}

Para Carnide (2012), a arquitetura efêmera é puramente experimental e está totalmente interligada às artes por permitir que o arquiteto tenha maior flexibilidade na hora de escolhas de materiais, técnicas e possibilidade de variadas vivências. Ainda segundo a autora, a arquitetura temporária, que revoga o seu próprio futuro para uma curta duração no presente é extremamente dramática e faz com que se intensifiquem as relações entre espaço, ambiente e pessoas. Para que tal arquitetura funcione, Carnide (2012) ressalta o uso de técnicas construtivas eficientes e com materiais totalmente alternativos, proporcionando ao arquiteto maneiras de fazer muito com pouco.

Scóz (2009) relata que mesmo que a obra efêmera tenha um curto prazo de duração, depois de desmontada deixa cicatrizes nos que vivenciam tais obras. A percepção pelo usuário da arquitetura efêmera é diferente da arquitetura perene segundo Scóz (2009), por haver uma espécie de estranhamento guiando os que utilizam desses conjuntos.

Grandes exemplos desse estilo arquitetônico são pavilhões das Exposições do século XIX que foram projetados no intuito de serem demolidos logo após o término destes eventos. Em alguns casos, esses pavilhões foram transferidos para novos locais, trazendo um novo uso para suas estruturas, como o Palácio de Cristal, projetado por Joseph Paxton em 1851 para a Exposição de Londres, que foi transferido após o termino do evento para Sydenhal Hill, onde passou a funcionar como museu. Tal obra era de fácil montagem e feita com materiais disponíveis na 
época, caiu no gosto popular e por esse motivo encontrou-se um novo uso em outro local (PAZ, 2008).

Todo tipo de espaço projetado pelo homem tem uma duração, seja ela por demolições, substituições ou ações do tempo, sendo assim o meio urbano está em constante mutação, principalmente nos dias atuais com o rápido acesso a informações e fácil comunicação entre diferentes locais do mundo, tornando cada vez mais efêmero a maneira de se viver na contemporaneidade (PAZ, 2008).

No âmbito de intervenções efémeras que desafiam a vivência tradicional dos espaços arquitetónicos, surgem ainda ações que decorrem dentro de edifícios pré-existentes e, portanto, através da inserção de determinados elementos estruturais ou decorativos modelam e reorganizam o espaço interior, dotando-o de novas qualidades sensíveis (CARNIDE, 2012, p.16).

A utilização de técnicas dessa arquitetura mutável vem para complementar o quanto a cidade está suscetível a transformações e como um espaço público pode ser palco de diversas experiências sociais e culturais por esse estilo arquitetônico possibilitar readaptações fáceis e dinâmicas.

O Campo de Cebada, em Madrid, serve de inspiração na hora de projetar espaços públicos com a apropriação da comunidade com êxito. O local multifuncional e multicultural é um exemplo de como um espaço público pode ser adaptável para vários usos, abrangendo várias partes da comunidade que está em seu entorno, além de ser didático através de suas oficinas. Tais mobiliários também são responsáveis por dar características flexíveis e mutáveis ao espaço, através de suas adaptações e liberdade de uso que propõe aos frequentadores do local. Um dos exemplos marcantes de mobiliário efêmero pode ser encontrado no local, por se tratar de uma base que se adapta à vários usos dependendo da sua necessidade.

\section{CONSIDERAÇÕES FINAIS}

Assim como as cidades, os espaços públicos sofrem constantes mutações. Tendo esses locais como de extrema importância para a vida em conjunto e por serem também palco de trocas multiculturais, há a necessidade de encontrar ações que tornem tais espaços em grandes atrativos para a sociedade contemporânea.

A arquitetura efêmera vem para complementar tais necessidades de constantes adaptações que a vida urbana oferece para os seus usuários, além de atender de maneira mais eficiente a demanda multicultural presenciada nos processos de integração da atualidade. Para essa vertente arquitetônica faz-se necessário o uso de materiais alternativos e trocas de experiências diversas, atendendo assim as necessidades para que um espaço público atinja seus objetivos primordiais de bom funcionamento.

\section{REFERÊNCIAS BIBLIOGRÁFICAS}

BARATTO, R. "Campo de Cebada” em Madri: um projeto local de autogestão artística. Disponível em: < http://www.archdaily.com.br/br/01-137915/campo-de-cebada-em-madri-um-projeto-localde-autogestao-artistica>. Acesso em: 02 jun. 2017.

CAMPOS FILHO, C. M. Reinvente seu bairro: Caminhos para você participar do planejamento de sua cidade. 2. ed. São Paulo: Editora 34, 2003.

CARNIDE, S. Arquiteturas expositivas efémeras: Pavilhão temporário em Roma. 2012. 92 f. Dissertação (Mestrado em Arquitetura) - Instituto Superior Técnico, Universidade de Lisboa. Lisboa - Portugal. 
CUNHA, R. Os espaços públicos abertos e as leis de uso e ocupação do solo: uma questão de qualidade para ambientes sustentáveis. In: ENECS - Encontro Nacional Sobre Edificações e Espaços Sustentáveis, 3., 2003, Salvador. Disponível em: < http://www.elecs2013.ufpr.br/wpcontent/uploads/anais/2003/2003_artigo_072.pdf>. Acesso em: 10 abr. 2017.

D’ADESKY, J. Pluralismo étnico e multiculturalismo. 1997. 182f. Tese (Doutorado) - Universidade de São Paulo, São Paulo - SP.

FRÚGOLI JR., H. São Paulo: Espaços públicos e interação social. 1. ed. São Paulo: Marco Zero, 1995.

GATTI, S. Espaços públicos. Diagnóstico e metodologia de projeto. 1. ed. São Paulo: ABCP, 2013. Disponível em: < http://www.solucoesparacidades.com.br/wpcontent/uploads/2013/11/Manual\%20de\%20espacos\%20publicos.pdf>. Acesso em: 10 abr. 2017.

JOVCHELOVITCH, S. Vivendo a vida com os outros: intersubjetividade, espaço público e representações sociais. GUARESCHI, P. et al. Textos em representações sociais. 6. ed. Petrópolis: Editora Vozes, 1995. p 63-85.

JÚNIOR, B.; HASS, I. Multiculturalismo e cidade: A diversidade cultural na política social urbana. Âmbito Jurídico, Rio Grande, XIV, n. 84, jan. 2011. Disponível em: <http://www.ambitojuridico.com.br/site/index.php?n_link=revista_artigos_leitura\&artigo_id=8922>. Acesso em: 14 fev. 2017.

MÁRQUEZ, L. El Campo de Cebada / La ciudad situada. Disponível em: < http://www.archdaily.com.br/br/01-136323/el-campo-de-cebada-slash-la-ciudad-situada>. Acesso em: 02 jun. 2017.

PAZ, D. Arquitetura efêmera ou transitória. Revista arquitextos. 2008. Disponível em: <http://www.vitruvius.com.br/revistas/read/arquitextos/09.102/97>. Acesso em: 14 fev. 2017.

PROGRAMA DAS NAÇÕES UNIDAS PARA O DESENVOLVIMENTO. Relatório do Desenvolvimento Humano 2004. Lisboa: Editora Mensagem, 2004. Disponível em: < http://hdr.undp.org/sites/default/files/hdr2004-portuguese.pdf>. Acesso em: 20 mar. 2017.

SCÓZ, E. Arquitetura efêmera: O repertório do arquiteto revelado em obras temporárias. 2009. 161 f. Dissertação (Mestrado em Design e Arquitetura) - Faculdade de Arquitetura e Urbanismo , Universidade de São Paulo. São Paulo - SP.

OLIVEIRA, N.; PADILLA, B. A diversidade como elemento de desenvolvimento/atração nas políticas locais urbanas: contrastes e semelhanças nos eventos de celebração intercultural. Revista da Faculdade de Letras da Universidade do Porto, Lisboa, n. temático: Imigração, Diversidade e Convivência Cultural, 2012. <Disponível em http://ler.letras.up.pt/uploads/ficheiros/10011.pdf>. Acesso em: 14 fev. 2017. 